\title{
Lifetime Abuse and Quality of Life among Older People
}

\author{
Silvia Fraga, Joaquim Soares, Maria Gabriella Melchiorre, Henrique Barros, Bahareh Eslami, \\ Elisabeth Ioannidi-Kapolou, Jutta Lindert, Gloria Macassa, Mindaugas Stankunas, \\ Francisco Torres-Gonzales, and Eija Viitasara
}

\begin{abstract}
Few studies have evaluated the impact of lifetime abuse on quality of life (QoL) among older adults. By using a multinational study authors aimed to assess the subjective perception of QoL among people who have reported abuse during the course of their lifetime. The respondents $(N=4,467 ; 2,559$ women) were between the ages of 60 and 84 years and living in seven European countries (Germany, Greece, Italy, Lithuania, Portugal, Spain, and Sweden). Lifetime abuse was assessed by using a structured questionnaire that allowed to assess lifetime experiences of abuse. QoL was assessed with the World Health Organization Quality of Life-Old module. After adjustment for potential confounders, authors found that to have had any abusive experience decreased the score of sensory abilities. Psychological abuse was associated with lower autonomy and past, present, and future activities. Physical abuse with injuries significantly decreased social participation. Intimacy was also negatively associated with psychological abuse, physical abuse with injury, and sexual abuse. The results of this study provide evidence that older people exposed to abuse during their lifetime have a significant reduction in QoL, with several QoL domains being negatively affected.
\end{abstract}

KEY WORDS: abuse; aging; quality of life; violence

A buse has immediate effects on health and in some cases is fatal. It has been established that exposure to abuse results in physical, mental, and behavioral health consequences (Krug, Dahlberg, Mercy, Zwi, \& Lozano, 2002). Maltreatment is a common and significant burden on the health care system that can produce sequelae, both short and long term (Buckingham \& Daniolos, 2013). In fact, the negative health consequences can persist long after the abuse has stopped.

A traumatic event such as abuse leads to potentially irreversible changes that may increase vulnerability to poor health over the life course (Repetti, Taylor, \& Seeman, 2002). We know that early exposure to violence can produce long-term consequences for the victim many years later (Child Welfare Information Gateway, 2017). Victims may develop at least one mental disorder such as depression, anxiety, posttraumatic stress, substance abuse, and chronic physical complaints (Buckingham \& Daniolos, 2013). Studies among women who were abused at any time after the age of 15 showed that they are significantly more likely than other women to report overall poor health, chronic pain, memory loss, and problems in walking and carrying out daily activities (GarcíaMoreno, Jansen, Ellsberg, Heise, \& Watts, 2005). Studies have also found that women with a history of abuse are later more likely than other women to report a range of chronic health problems such as headaches, chronic pelvic pain, back pain, abdominal pain, irritable bowel syndrome, and gastrointestinal disorders (Campbell, 2002; Campbell et al., 2002).

In addition, abuse may have an impact on the victim's life expectancy and long-term health-related quality of life (QoL). The linkage between abuse and perceived QoL (Corso, Edwards, Fang, \& Mercy, 2008; Dong, Simon, \& Gorbien, 2007; O’Keeffe et al., 2007; Soares et al., 2013) has not attracted great attention. However, existing studies suggest that abuse or neglect experiences are associated with lower QoL in most domains (Soares et al., 2013). Furthermore, a study has shown that people who have experienced violence, for instance, reported significant losses in health-related QoL in adulthood compared with people who did not experience maltreatment (Corso et al., 2008). Also, in that study it was shown that childhood maltreatment had a yearly loss of 0.03 quality adjusted life years, or 11 days per year (Corso et al., 2008). 
Nevertheless, there are few studies on the relationship between abuse and perceived QoL, particularly lifetime abuse and among older people (Evren et al., 2011). A further examination of the topic may be useful to assess the burden of abuse on health. This information may help policymakers and health planners in the development of effective interventions to target abuse and improve QoL among victims of abuse (Soares et al., 2013).

Based on data collected in a multinational study on abuse and health in seven European countries, we intended to assess the subjective perception of QoL among people between the ages of 60 and 84 years who have experiences abuse during their lifetime.

\section{METHOD}

\section{Participants}

The present study is based on data collected in the scope of Elder Abuse: A Multinational Prevalence Survey. This is a cross-sectional study with recruitment and data collection in the seven European cities conducted during the period between January and July 2009 by means of face-to-face interviews or a combination of interviews and selfresponse questionnaires. The data became available for processing in 2011 after input and creation of indexes. All scales (if not available) were translated into the native languages spoken in the countries were the data were collected, back-translated, and culturally adapted. The same procedure was applied for other materials (for example, information letters). The respondents were informed (in writing or verbally) about the research and informed consent was obtained. Confidentiality, anonymity, and the respondent's rights were emphasized. Ethical permission was applied for and received in each country (for further details, see Lindert et al., 2013; Lindert et al., 2011; Macassa et al., 2013; Soares et al., 2010).

The sample consisted of 4,467 randomly selected respondents $(2,559$ of them women) between the ages of 60 and 84 years (Lindert et al., 2011). The respondents included in the survey had no cognitive (for example, dementia) or sensory (for example, blindness) impairments, were national citizens or documented migrants, and resided in their own or rented houses or homes for elderly people. Mean response rate across countries was 45.2 percent. More details on sample (including demographic and socioeconomic data), sampling strategy, and response rates are published elsewhere (Lindert et al., 2013; Lindert et al., 2011; Macassa et al., 2013).

\section{Measures}

Abuse. Abuse was assessed with 52 questions based on the revised Conflict Tactics Scales (Straus, Hamby, Boney-McCoy, \& Sugarman, 1996) and on the UK survey of elder abuse and neglect (O'Keeffe et al., 2007). Psychological Abuse subscale comprised 11 questions (for example, whether someone undermined or belittled what you do), of which six consisted of severe acts; physical abuse 17 questions (for example, whether someone used a knife, a gun, or other weapon on you), of which 10 consisted of severe acts; physical abuse with injury seven questions (for example, whether you passed out from being hit on the head), of which four consisted of severe acts; sexual abuse eight questions (for example, whether someone tried to have sexual intercourse with you against your will), of which five consisted of severe acts; financial abuse nine questions (for example, whether someone used fraud to take your money or possessions from you), of which five consisted of severe acts. Each abuse act may have occurred once, twice, three to five, six to 10 , 11 to 20 , or more than 20 times after the age of 18 . For each subscale, lifetime abuse was defined if participants positively reported the occurrence of these acts at least once during adult life. When questions were answered this has never happened, the respondent was coded as non-case (0), and if they answered yes as a case (1). Cronbach's alphas across countries for each violence type as assessed by the scale were .82 for psychological abuse, .80 for physical abuse, .70 for physical abuse with injury, .90 for sexual abuse, and .81 for and financial abuse. The present study focused on lifetime abuse, that is, exposure to any of the abovementioned abuse from the age of 18 years, which does not include child abuse.

QoL. QoL was assessed with the World Health Organization Quality of Life-Old (WHOQOLOLD) module (Power, Quinn, \& Schmidt, 2005b). It contains 24 items, with responses graded on a Likert-type scale ranging from $1=$ not at all to $5=$ extremely; we transformed the scale scores to between 0 and 100, making it possible to express the scale score in percentage between the lowest $(0)$ and highest (100) possible value. To obtain the transformed facet score (0-100), the manual instructions of the scale administration have been taken (Power et al., 2005b). The following transformation rule was applied: Transformed scale score $=6.25 \times$ (raw facet score -4$)$. The items can be summed into a total QoL and divided into six domains with four items in 
each: autonomy (for example, freedom to make own decisions); fear of death or dying; intimacy (for example, feeling a sense of companionship in life); past, present, and future activities (for example, satisfaction with one's achievements); sensory abilities (for example, loss of sight affecting participation in activities); and social participation (for example, having enough to do each day). Higher scores indicate higher QoL. Cronbach's alpha (standardized items) for QoL across the included countries was .92.

\section{Statistical Analyses}

In the present analysis, analysis of variance was used to compare means of each domain of QoL according to each type of lifetime abuse experience. Seven multiple linear regressions were computed to scrutinize the associations between the dependent variables (sensory abilities; autonomy; intimacy; past, present, and future activities; social participation; fear of death and dying; and total QoL) and each form of lifetime abuse (psychological, physical, financial, sexual, physical with injury, and abuse overall). Models were adjusted for country of residence, age, gender, living with partner, marital status, education, occupation, financial support, financial strain, social support, smoking, alcohol drinking, body mass index, and presence of disease. Associations were expressed as unstandardized $\beta$ s and their 95 percent confidence intervals (CI). To assess multicollinearity in our regression analysis, we calculated the variance inflation factors (VIF) for estimates in each model. Results showed VIF values lower than 5, which indicates that regression coefficients were not poorly estimated due to multicollinearity. As no significant statistical interaction by gender in the association between lifetime abuse and QoL was found, data for men and women were analyzed together.

\section{RESULTS}

As shown in Table 1, 45.5 percent of the participants reported at least one experience of abuse during their lifetime, with psychological abuse as the most common type ( 34.5 percent). The prevalence of lifetime physical abuse was 11.5 percent, injury 4.3 percent, sexual abuse 5 percent, and financial abuse 18.5 percent. Significant statistical differences were observed in the prevalence of lifetime abuse according to gender. Women tend to report more frequently experiences of lifetime injuries and sexual and financial abuse. Table 2 shows the prevalence of severe episodes of abuse according to country, age, and gender. Severe episodes of physical abuse and financial abuse were reported in higher numbers in Portugal.

As shown in Table 3, the mean and standard deviation score of total WHOQOL-OLD was significantly higher among the nonabused compared with those who reported psychological abuse during their lifetime. This difference was also observed for physical abuse, physical abuse with injuries, and sexual abuse. In addition, lifetime psychological abuse was significantly associated with lower levels of autonomy; past, present, and future activities; social participation; and intimacy. Similar results were found for physical abuse, physical abuse with injuries, and sexual abuse. Financial abuse was significantly associated with lower levels of autonomy; past, present, and future activities; and social participation. Furthermore, victims of physical abuse, physical abuse with injuries, or sexual abuse reported lower levels of sensory abilities, although differences were not statistically significant for sexual abuse. However, the relationship of sensory abilities with psychological or financial abuse showed opposite results. That is, higher scores of sensory abilities were observed among victims of psychological and financial abuse. The death and dying domain was not associated with abusive experiences during the course of a lifetime.

Table 4 shows the results for the linear regressions considering each domain of QoL. After adjustment for potential confounders, it was observed that experience

Table 1: Lifetime Abuse Prevalence (\%) among People Ages 60 to 84 Years in Seven European Countries $(N=4,467)$

\begin{tabular}{lcccccc} 
Respondents & Psychological & Physical & Physical with Injury & Sexual & Financial & Any \\
\hline Overall & 34.5 & 11.5 & 4.3 & 5.0 & 18.5 & 45.5 \\
Gender & & & & & & \\
$\quad$ Female & 34.7 & 11.8 & 5.4 & 6.6 & 20.3 & 47.0 \\
Male & 34.3 & 11.2 & 2.8 & 2.7 & 16.0 & 43.5 \\
$\quad$ value & .772 & .567 & $<.001$ & $<.001$ & $<.001$ & .023 \\
\hline
\end{tabular}




\begin{tabular}{lccccc}
\multicolumn{5}{c}{ Table 2: Prevalence (\%) of Severe Abuse (by Each Type) according to Country, Age, and } \\
Gender \\
Variable & Psychological & Physical & Physical with Injury & Sexual & Financial \\
\hline Country & & & & & \\
$\quad$ Germany & 23.3 & 8.9 & 3.7 & 6.5 & 9.4 \\
Greece & 6.8 & 4.4 & 1.7 & 3.1 & 3.1 \\
Italy & 5.3 & 0.8 & 0 & 1.1 & 18.8 \\
Lithuania & 15.2 & 2.5 & 1.0 & 0.2 & 3.5 \\
Portugal & 33.7 & 16.0 & 5.5 & 5.9 & 40.4 \\
Spain & 13.2 & 7.2 & 4.4 & 2.4 & 24.5 \\
Sweden & 22.8 & 5.9 & 2.7 & 2.9 & 4.2 \\
$p$ value & $<.001$ & $<.001$ & $<.001$ & $<.001$ & $<.001$ \\
Age (years) & & & & & \\
60-64 & 19.2 & 8.2 & 3.1 & 3.6 & 12.5 \\
65-69 & 17.5 & 6.3 & 2.4 & 3.3 & 13.9 \\
$70-74$ & 18.4 & 6.2 & 3.2 & 3.6 & 16.5 \\
$75-79$ & 15.0 & 5.7 & 2.4 & 2.4 & 15.5 \\
$80-84$ & 13.9 & 5.9 & 2.0 & 2.2 & 18.5 \\
$p$ value & .027 & .174 & .553 & .377 & .009 \\
Gender & & & & & 17.3 \\
Female & 18.1 & 6.5 & 3.3 & 4.5 & 11.9 \\
Male & 16.1 & 6.7 & 2.0 & 1.3 & $<.001$ \\
\hline value & .078 & .903 & .009 & $<.001$ & \\
\hline
\end{tabular}

of lifetime physical abuse with injuries decreased by 4.14 (95\% CI: $-7.45,-0.84$ ) the score of sensory abilities. Psychological abuse was associated with lower levels of autonomy $(\beta=-2.38,95 \% \mathrm{CI}:-4.46,-0.30)$ and past, present, and future activities $(\beta=-2.95,95 \%$ CI: $-4.68,-1.22)$. Also, physical abuse with injuries significantly decreased social participation $(\beta=-2.86$, $95 \%$ CI: $-5.67,-0.06)$. Moreover, intimacy was negatively associated with psychological abuse $(\beta=-3.51$, 95\% CI: $-6.29,-0.72)$, physical abuse with injury $(\beta=-5.00,95 \% \mathrm{CI}:-9.11,-0.89)$, and sexual abuse $(\beta=-4.05,95 \% \mathrm{CI}:-7.53,-0.56)$. In general, the total score of QoL decreased with psychological abuse and physical abuse with injuries.

\section{DISCUSSION}

Almost half of the participants reported at least one type of abuse during their lifetime; psychological abuse was the most frequent form. Although less attention has been given to emotional abuse compared with other forms (such as physical abuse) (O'Laeary, 1999), it is known that such abuse may have a high negative impact on people's well-being. Psychological abuse over time may lead to depression, fear, anxiety, and low self-esteem (Ellsberg, Jansen, Heise, Watts, \& García-Moreno, 2008), and ultimately to a high incidence of suicide and suicidal attempts (Kapoor, 2000).
Our study showed that people who experienced abuse during their lifetime had lower scores in QoL dimensions, compared with people who did not experience any type of abuse. A previous study also showed that people who experienced abuse early in life have a marginal decrease in at least two years of undiscounted quality-adjusted life expectancy, compared with people who did not experience abuse (Corso et al., 2008). It seems that lifetime experiences get under the skin, and may have a negative impact on individuals' later QoL.

After adjustment for potential confounders, it was observed in our study that sensory abilities and social participation were significantly associated with lifetime physical abuse with injuries. Having had an abusive experience decreased the score of sensory abilities by 4.14 (95\% CI: $-7.45,-0.84)$ and of social participation by 2.86 (95\% CI: -5.67 , $-0.06)$. Lifetime abuse seems to have had a negative influence on the ability to have personal and intimate relationships. Over time, feelings like worthlessness, powerlessness, hopelessness, unhappiness, and insecurity can be instigated by abuse experiences and then incorporated in the individuals' health and QoL. Even the experience of psychological abuse was related to lower levels of autonomy; intimacy; and past, present, and future activities. It has been previously shown that psychological 


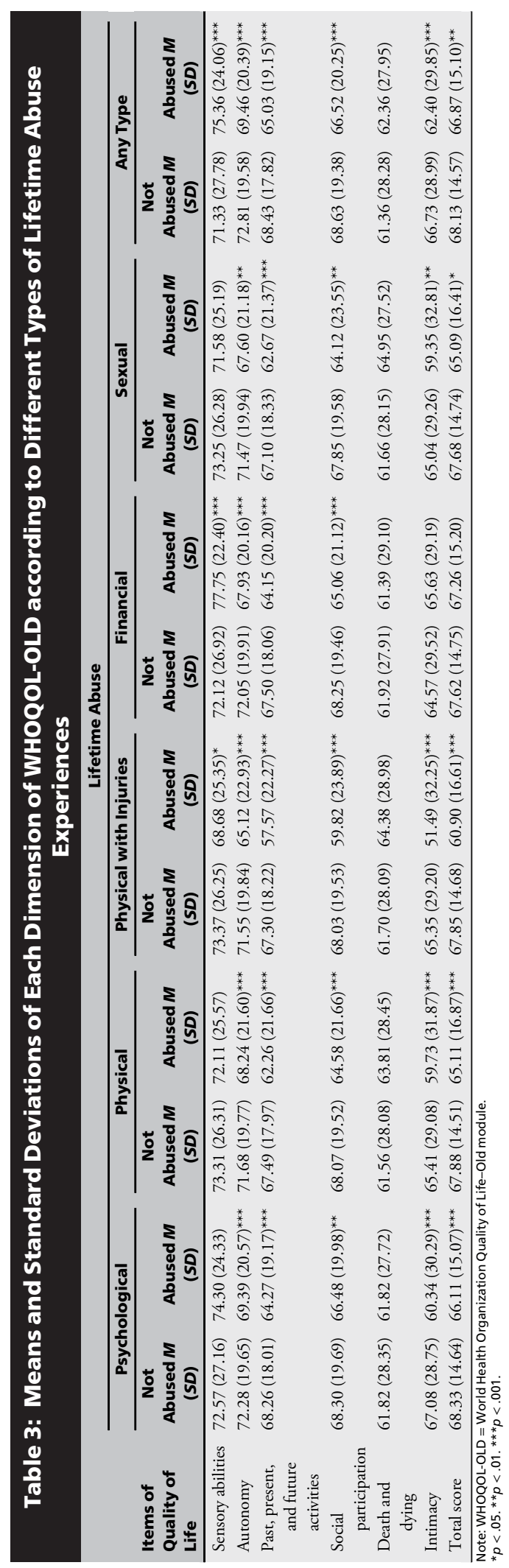




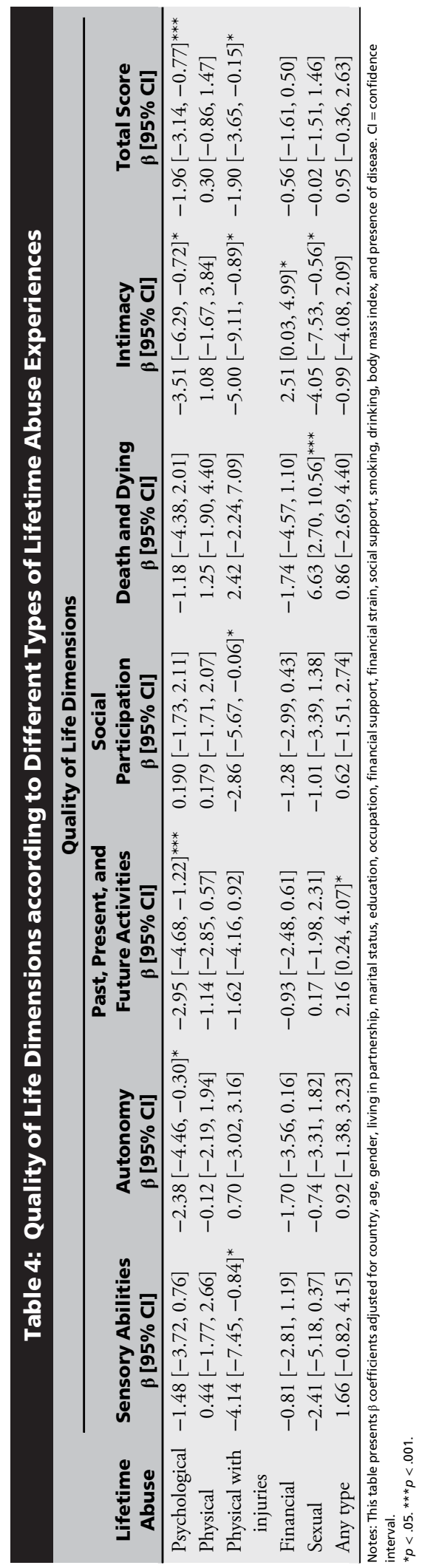

abuse may be more damaging than other forms of abuse (Acierno et al., 2010). Moreover, it has been suggested that if the abuse was perpetrated by someone close to the victim, it may be highly stressful for the individual, particularly in terms of intimacy (Gray, 2009; Soares et al., 2013).

\section{Limitations}

The strength of this study lies in its large sample and multicountry approach. In addition, it explores a research topic that has been little studied in Europe. However, there are some limitations that should be discussed. The cross-sectional nature of this study did not allow conclusions about causality. Information was collected retrospectively, which may have resulted in recall bias. In our study we used the WHOQOL-OLD, which is the most appropriate instrument to assess QoL among older people, although there are other instruments available. However, WHOQOL allowed a cross-cultural comparison (Power, Quinn, \& Schmidt, 2005a) and also comprises a generic measure of QoL, making it ideal for adaptation to the assessment of QoL in older adults with good psychometric performance (Power et al., 2005a). The reliability of older age groups in selfreporting events that may have occurred many years ago can be questioned. However, there is evidence suggesting that the unreliability of retrospective reports of trauma is overstated (Hardt \& Rutter, 2004). In fact, traumatic events tend to be memorable. Furthermore, in older age, when the maltreatment has ended, there is an increased likelihood of disclosure (Ghetti et al., 2006). On the other hand, we are aware that some cases of abuse have not been self-identified as an abusive experience.

\section{Practice Implications}

This study showed that experiences of violence have a negative impact in QoL and also seem to affect the aging process. First, this study highlights the importance of screening for violence early in life, when these experiences have a negative impact in QoL. The identification and assessment of interpersonal violence experiences is a difficult process because this is not a visible problem, and the disclosure of such experiences is very dependent on the individual intention. Therefore an appropriate setting is required to gather this type of information. Social workers are the professionals with appropriate training to identify and assess interpersonal violence experiences in different 
settings, using multiple sources of information. These professionals are prepared with empathy skills to deal with interpersonal difficulties. In research, social workers are prepared to provide training to other professionals to effectively use screening tools. They are also able to provide the appropriate support, for instance, in the context of violence research. Social workers usually collaborate with organizations or associations that would effectively respond to victims. Identifying and assessing the problem contributes to monitoring it in society. However, we also need a holistic understanding of violence to shape the interventions efforts. Social workers and other professionals should work collaboratively in this task.

Second, to improve QoL and well-being has increasingly become an essential issue for societies. Social workers and other professionals should work closely together to assess population needs, particularly those of vulnerable populations such as older people, to define appropriate actions to reduce the impact of abuse for QoL.

\section{Conclusion}

Our results provide evidence that older people exposed to abuse during their lifetime have a significant reduction in QoL, with several QoL domains being negatively affected by an abusive experience. Further research should be conducted to better understand violence phenomena among the population, particularly vulnerable population groups, and to define interventions to reduce the impact of traumatic experiences on QoL. HSW

\section{REFERENCES}

Acierno, R., Hernandez, M. A., Amstadter, A. B., Resnick, H. S., Steve, K., Muzzy, W., \& Kilpatrick, D. G. (2010). Prevalence and correlates of emotional, physical, sexual, and financial abuse and potential neglect in the United States: The National Elder Mistreatment Study. American Journal of Public Health, 100, 292-297. doi:10.2105/ajph.2009.163089

Buckingham, E. T., \& Daniolos, P. (2013). Longitudinal outcomes for victims of child abuse. Current Psychiatry Reports, 15(2), 342. doi:10.1007/s11920-012-0342-3

Campbell, J. C. (2002). Health consequences of intimate partner violence. Lancet, 359(9314), 1331-1336. doi:10.1016/S0140-6736(02)08336-8

Campbell, J., Jones, A. S., Dienemann, J., Kub, J., Schollenberger, J., O'Campo, P., et al. (2002). Intimate partner violence and physical health consequences. Archives of Internal Medicine, 162, 1157-1163.

Child Welfare Information Gateway. (2017, April). Child abuse and neglect fatalities 2015: Statistics and interventions [Numbers and Trends fact sheet]. Retrieved from http://www.childwelfare.gov/pubs/factsheets/ fatality.pdf
Corso, P. S., Edwards, V. J., Fang, X., \& Mercy, J. A. (2008). Health-related quality of life among adults who experienced maltreatment during childhood. American Journal of Public Health, 98, 1094-1100. doi:10.2105/AJPH.2007.119826

Dong, X., Simon, M. A., \& Gorbien, M. (2007). Elder abuse and neglect in an urban Chinese population. Journal of Elder Abuse \& Neglect, 19(3-4), 79-96. doi:10.1300/J084v19n03_05

Ellsberg, M., Jansen, H., Heise, L., Watts, C., \& GarcíaMoreno, C. (2008). Intimate partner violence and women's physical and mental health in the WHO MultiCountry Study on Women's Health and Domestic Violence: An observational study. Lancet, 371, 1165-1172.

Evren, C., Sar, V., Dalbudak, E., Cetin, R., Durkaya, M., Evren, B., \& Celik, S. (2011). Lifetime PTSD and quality of life among alcohol-dependent men: Impact of childhood emotional abuse and dissociation. Psychiatry Research, 186(1), 85-90. doi:10.1016/j.psychres .2010 .07 .004

García-Moreno, C., Jansen, H.A.F.M., Ellsberg, M., Heise, L., \& Watts, C. (Eds.). (2005). WHO MultiCountry Study on Women's Health and Domestic Violence against Women: Initial results on prevalence, health outcomes and women's responses. Geneva: World Health Organization.

Ghetti, S., Edelstein, R. S., Goodman, G. S., Cordon, I. M., Quas, J. A., Alexander, K. W., et al. (2006). What can subjective forgetting tell us about memory for childhood trauma? Memory \& Cognition, 34, 1011-1025.

Gray, A. (2009). The social capital of older people. Ageing $\mathcal{E}$ Society, 29, 5-31.

Hardt, J., \& Rutter, M. (2004). Validity of adult retrospective reports of adverse childhood experiences: Review of the evidence. Journal of Child Psychology and Psychiatry, 45, 260-273.

Kapoor, S. (2000). Domestic violence against women and girls (Innocenti Digest No. 6). Florence, Italy: United Nations Children's Fund (UNICEF) and Innocenti Research Center.

Krug, E. G., Dahlberg, L. L., Mercy, J. A., Zwi, A. B., \& Lozano, R. (Eds.). (2002). World report on violence and health. Geneva: World Health Organization.

Lindert, J., de Luna, J., Torres-Gonzales, F., Barros, H., Ioannidi-Kopolou, E., Melchiorre, M. G., et al. (2013). Abuse and neglect of older persons in seven cities in seven countries in Europe: A cross-sectional community study. International Journal of Public Health, 58(1), 121-132. doi:10.1007/s00038-012-0388-3

Lindert, J., Luna, J., Torres-Gonzalez, F., Barros, H., Ioannidi-Kapolou, E., Quattrini, S., et al. (2011). Study design, sampling and assessment methods of the European study 'abuse of the elderly in the European region'. European Journal of Public Health, 22, 662-666. doi:10.1093/eurpub/ckr079

Macassa, G., Sundin, O., Viitasara, E., Barros, H., TorresGonzales, F., Ioannidi-Kapolou, E., et al. (2013). Psychological abuse among older persons in Europe: A cross-sectional study. Journal of Aggression, Conflict and Peace Research, 5(1), 16-34.

O'Keeffe, M., Hills, A., Doyle, M., McCreadie, C., Scholes, S., Constantine, R., et al. (2007). UK study of abuse and neglect of older people: Prevalence survey report. London: Department of Health.

O’Laeary, K. D. (1999). Psychological abuse: A variable deserving critical attention in domestic violence. Violence and Victims, 14, 3-23.

Power, M., Quinn, K., \& Schmidt, S. (2005a). Development of the WHOQOL-old module. Quality of Life Research, 14, 2197-2214. doi:10.1007/s11136-005-7380-9 
Power, M., Quinn, K., \& Schmidt, S. (2005b). WHOQOLOLD Group: Development of the WHOQOL-Old module. Quality of Life Research, 14, 2197-2214.

Repetti, R. L., Taylor, S. E., \& Seeman, T. E. (2002). Risky families: Family social environments and the mental and physical health of offspring. Psychological Bulletin, 128, 330-366.

Soares, J.J.F., Barros, H., Torres-Gonzales, F., IoannidiKapolou, E., Lamura, G., Lindert, J., et al. (2010). Abuse and health among elderly in Europe. Kaunas: Lithuanian University of Health Sciences Press.

Soares, J.J.F., Sundin, O., Viitasara, E., Melchiorre, M. G., Stankunas, M., Lindert, J., et al. (2013). Quality of life among persons aged 60-84 years in Europe: The role of psychological abuse and socio-demographic, social and health factors. Biosafety $\&$ Health Education, 1(1), 1-12. doi:10.4172/2332-0893.1000101

Straus, M. A., Hamby, S. L., Boney-McCoy, S., \& Sugarman, D. B. (1996). The revised Conflict Tactics Scales (CTS2): Development and preliminary psychometric data. Journal of Family Issues, 17, 283-316.

Silvia Fraga, PhD, is a postdoctoral researcher, EPIUnit-Instituto de Saúde Pública da Universidade do Porto, Rua das Taipas 135/ 139, Porto, 4050-600, Portugal; e-mail: silfraga@med.up.pt. Joaquim Soares, $\mathbf{P h D}$, is associate professor, Department of Public Health Science, Mid Sweden University, Sundsvall, Sweden. Maria Gabriella Melchiorre, $\mathbf{P h D}$, is social gerontologist and economist, Center for Socioeconomic Research on Aging, Ancona, Italy. Henrique Barros, PhD, is professor, EPIUnit-Instituto de
Saúde Pública da Universidade do Porto, Porto, Portugal. Bahareh Eslami, PhD, is a postdoctoral researcher, Department of Public Health Science, Mid Sweden University, Sundsvall, Sweden. Elisabeth Ioannidi-Kapolou, PhD, is associate professor, Department of Sociology, National School of Public Health, Athens, Greece. Jutta Lindert, PhD, is professor, Department of Public Health, University of Emden, Emden, Germany, and Women's Studies Research Center, Brandeis University, Waltham, MA. Gloria Macassa, PhD, is associate professor, Public Health Sciences and Epidemiology, University of Gavle, Sweden. Mindaugas Stankunas, PhD, is professor, Department of Health Management, Lithuanian University of Health Sciences, Kaunas, Lithuania, and Department of Health Service Management, Centre for Health Innovation, School of Medicine, University of Griffith, Gold Coast, QLD, Australia. Francisco TorresGonzales, $\mathbf{P h D}$, is professor emeritus, Network of Biomedical Research on Mental Health Centers, University of Granada, Granada, Spain. Eija Viitasara, PhD, is associate professor, Department of Health Sciences, Mid Sweden University, Sundsvall, Sweden.

Original manuscript received August 9, 2016

Final revision received October 17, 2016

Editorial decision October 24, 2016

Accepted October 25, 2016

Advance Access Publication August 31, 2017

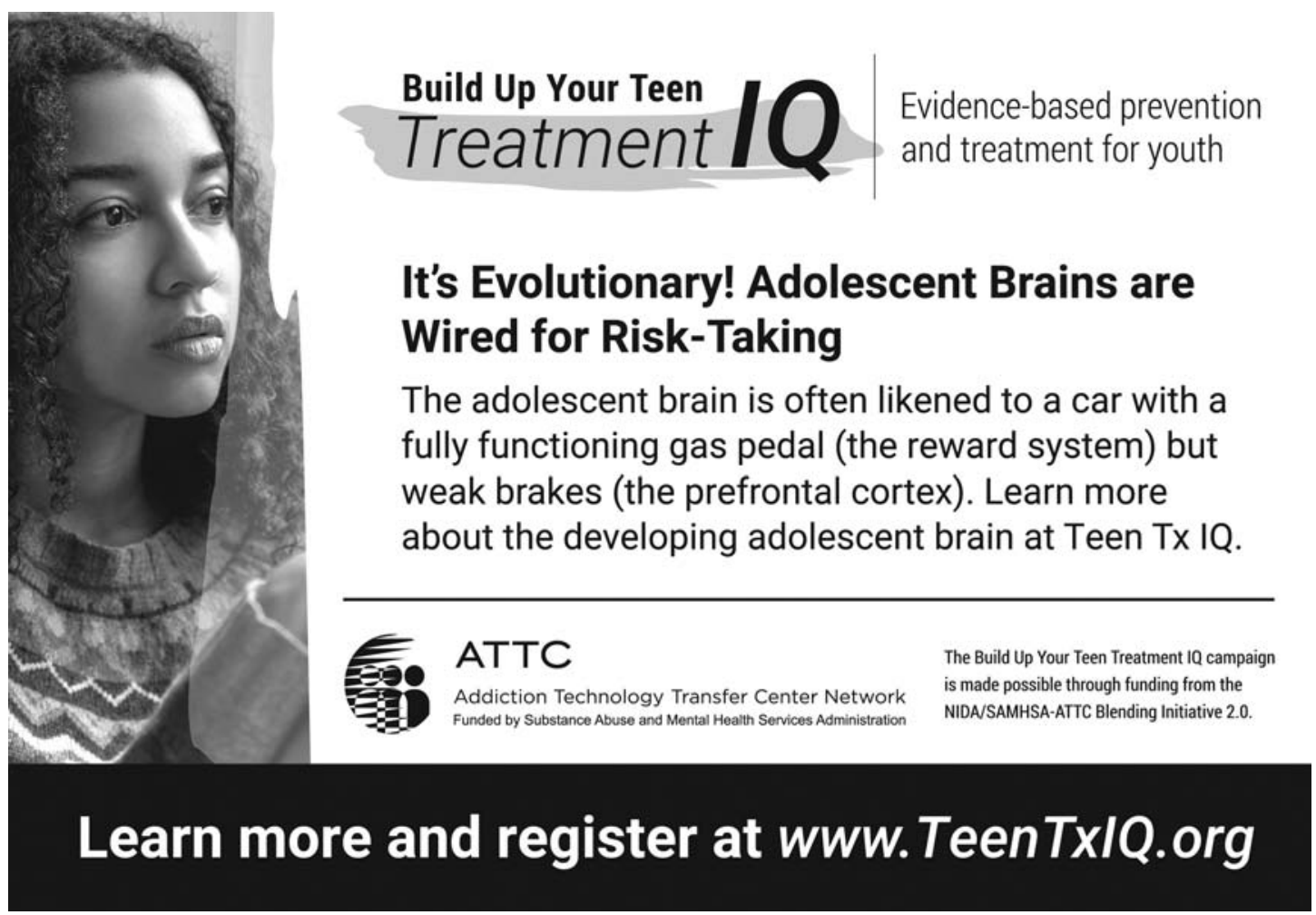

